\title{
Low intensity pulsed ultrasound (LIPUS) use for the management of instrumented, infected, and fragility non-unions: a systematic review and meta-analysis of healing proportions
}

Ross Leighton ${ }^{1}$, Mark Phillips ${ }^{2 *}$, Mohit Bhandari ${ }^{2,3}$ and Robert Zura ${ }^{4}$

\begin{abstract}
Background: Non-union occurs in approximately 5 to $10 \%$ of fracture patients, with certain bones at greater risk of failing to heal. Non-unions have a significant impact on socioeconomic costs and the patients short and long-term quality of life. Low intensity pulsed ultrasound (LIPUS) is a non-invasive therapy for non-union treatment that can improve the long-term outcome. The purpose of this study is to summarize the available literature assessing LIPUS potential to improve the union rate in instrumented, infected, and fragility non-unions.

Methods: A literature search was conducted in the MEDLINE, EMBASE, and CINAHL databases for all relevant literature on the healing rates of LIPUS utilized in instrumented, infected, and fragility non-unions. Study characteristics were summarized for each of the included studies. The percentage of healed patients (healing rate), for instrumented, infected, and fragility fracture non-union patients were pooled from each included study.

Results: The literature search identified a total of 326 articles, while searching reference lists and grey literature identified an additional 3 articles. There was a total of 29 articles included in this review, with 20 articles included within the quantitative synthesis of healing rates. The most common design of included studies was case series (17 articles), followed by case reports (9 articles). Studies were primarily retrospective (18 studies), with an additional 10 prospective studies. Non-union healing rates were $82 \%$ (95\% Cl: 76 to $87 \%$ ) in instrumented, $82 \%$ (95\% Cl: 70 to 95\%) in infected, and 91\% (95\% Cl: 87 to 95\%) in fragility fracture patients with non-unions.

Conclusion: This study has provided a thorough overview of the current literature on LIPUS treatment for instrumented, infected, and fragility fracture non-unions. The healing rates for non-unions in these subgroups were comparable to healing rates observed with LIPUS use in general non-union literature. LIPUS treatment should be considered as a conservative non-surgical treatment option to potentially reduce the socioeconomic impact and improve the quality of life of these unfortunate patients.
\end{abstract}

Level of evidence: 4 (systematic review of primarily case series data)

\footnotetext{
* Correspondence: phillimr@mcmaster.ca

${ }^{2}$ Department of Health Research Methods, Evidence, and Impact, McMaster University, Hamilton, Ontario, Canada

Full list of author information is available at the end of the article
}

C C The Author(s). 2021 Open Access This article is licensed under a Creative Commons Attribution 4.0 International License, which permits use, sharing, adaptation, distribution and reproduction in any medium or format, as long as you give appropriate credit to the original author(s) and the source, provide a link to the Creative Commons licence, and indicate if changes were made. The images or other third party material in this article are included in the article's Creative Commons licence, unless indicated otherwise in a credit line to the material. If material is not included in the article's Creative Commons licence and your intended use is not permitted by statutory regulation or exceeds the permitted use, you will need to obtain permission directly from the copyright holder. To view a copy of this licence, visit http://creativecommons.org/licenses/by/4.0/. The Creative Commons Public Domain Dedication waiver (http://creativecommons.org/publicdomain/zero/1.0/) applies to the data made available in this article, unless otherwise stated in a credit line to the data. 


\section{Background}

Non-union occurs in approximately 5 to $10 \%$ of fracture patients, with certain bones at greater risk of failing to heal $[1,2]$. There are a number of comorbidities that increase the risk of non-union, including smoking, alcoholism, obesity, osteoarthritis, rheumatoid arthritis, and type 2 diabetes [1, 3]. Previous use of certain medications, such as opioids or anticoagulants or smoking can also increase the risk of non-union [1]. Ultimately, the risk of nonunion is a multifaceted combination of fracture severity, location, comorbidities, and other medication use [1].

Non-unions have a significant impact on the quality of life of patients due to a need for further interventions, which is often additional surgery. Surgical management of non-unions also creates a large socioeconomic impact for both patients and the healthcare system [4, 5]. Estimates suggest that the cost of non-union management is $\$ 25,556$ per patient, with increased need for opioids, and substantial increased use of the health care system [5]. Non-unions that occur in instrumented, fragility fractures, or infected fractures can be particularly challenging to manage $[6,7]$. These non-union subgroups are associated with increased risks of further complications, which can increase the socioeconomic impact to the patient and their families. Avoiding the need for additional surgery through conservative management of nonunions can have a substantial benefit to patients and the healthcare system alike, if the nonunion can be resolved nonoperatively.

Low intensity pulsed ultrasound (LIPUS) is a wellrecognized non-invasive therapy for non-union treatment. This therapy provides a low-intensity ultrasound signal to the fracture site [6]. LIPUS's original FDA approved indications were for healing non-unions (excluding skull and vertebrae) and accelerating time to healing of fresh fractures of the tibia and radius [6].. Recently, LIPUS (EXOGEN Ultrasound Bone Healing System, Bioventus, Durham North Carolina) indications have been updated to include treatment of fragility fractures, instrumented fractures, and infected non-unions. Due to these updated indications, it is important to provide the available data from the literature to support LIPUS use in these particularly problematic non-union cases. The purpose of this study is to summarize the available literature assessing LIPUS (EXOGEN) heal rates in instrumented, infected, and fragility fracture non-unions.

\section{Methods}

\section{Literature search}

This review followed the PRISMA guidance for systematic review reporting [8]. A literature search was conducted in the MEDLINE, EMBASE, and CINAHL databases with no limits on the year of publication (Additional file 1). The reference lists of included studies were also hand-searched to identify any eligible studies that the search did not capture. Only articles published in English were included.

\section{Study selection}

Studies were screened in duplicate at the title/abstract and full text stage. All articles that were included by at least one reviewer at the title/abstract stage proceeded to full text review. Any disagreements in eligibility at the full text stage were resolved via consensus meetings. Studies that met the following inclusion criteria were eligible: 1) Use of LIPUS (EXOGEN) for non-union/delayed union fracture management, 2) Healing rate is reported as an outcome, 3) Healing rates must be reported for at least one of the risk groups of; fragility fracture non-unions, instrumented non-unions, or infected non-unions, and 4) Primary investigations on humans. The following exclusion criteria were used:1) Use of LIPUS for conditions other than non-unions, 2) Use of non-LIPUS bone growth stimulators, 3) Use of LIPUS in fresh fractures, 4) Use of LIPUS in conjunction with other non-union treatments, 5) Systematic reviews, literature reviews, or evidence synthesis publications, as these are not primary investigations, and 6) Animal studies.

\section{Data extraction}

All data was extracted using a standardized data extraction form. Study characteristic data on the country, study design, prospective/retrospective enrollment, number of participants, mean age, percentage male and female, and bones treated were collected for each of the included studies. Any manuscripts that were proven to be assessing the same patient sample were considered a single study in order to avoid double counting of patients. Non-union and delayed union classification was determined at the original author's discretion.

\section{Outcomes}

The raw number of healed patients was extracted from each included study, as well as the percentage of healed patients (healing rate), for instrumented, infected, and fragility fracture non-union patients. If specific numbers for instrumented, infected, and fragility fracture nonunion groups were not provided, a study was categorized in a subgroup if $80 \%$ or more of its patients were within one category.

\section{Data analysis}

Study heal rates were analyzed as pooled proportions. Case reports were not included within the pooled analysis, as they are not capable of providing an actual incidence of healing. A simple assessment of healing rates, such as counts and percentages, were reported as the total " $\mathrm{n}$ " of healed patients across all studies divided by the total sample size across all studies. Pooled analysis of 
proportions was conducted using the OpenMeta software. All pooled proportions were reported with their associated 95\% confidence intervals (CI). Analyses were conducted using a random effects model, and $\mathrm{I}^{2}$ was reported to summarize heterogeneity.

\section{Results}

\section{Study selection}

The literature search identified a total of 326 articles, while searching reference lists and grey literature identified an additional 3 articles. After title and abstract screening, 89 articles were eligible for full text screening. There was a total of 29 articles included in this review [9-37]. There were 20 articles included in our quantitative analysis, while the other 9 articles were case reports. There were 17 articles that provided heal rates for instrumented non-unions, 3 articles reporting fragility fracture non-unions, and 6 articles reporting on infected non-unions. A detailed summary of the article screening process is provided within Fig. 1.

\section{Study characteristics}

The most common design of included studies was case series (17 articles), followed by case reports ( 9 articles). The location of research was most frequently Japan (6 studies), followed by Germany (5 studies). Studies were primarily retrospective (18 studies), with 10 prospective studies included in this review. One study combined a retrospective dataset with additional data that was captured prospectively. Studies ranged in sample size from single case reports to a series of 1359 consecutive patients, and included a wide variety of bones treated. The mean age in included studies ranged from 17 to 77 , and studies included different proportions of females and males, ranging from exclusively males to exclusively females. Detailed individual study characteristics are provided in Table 1.

\section{Pooled healing rates}

Healing rates within each of the included studies are provided in Table 2. A total of 793 patients were

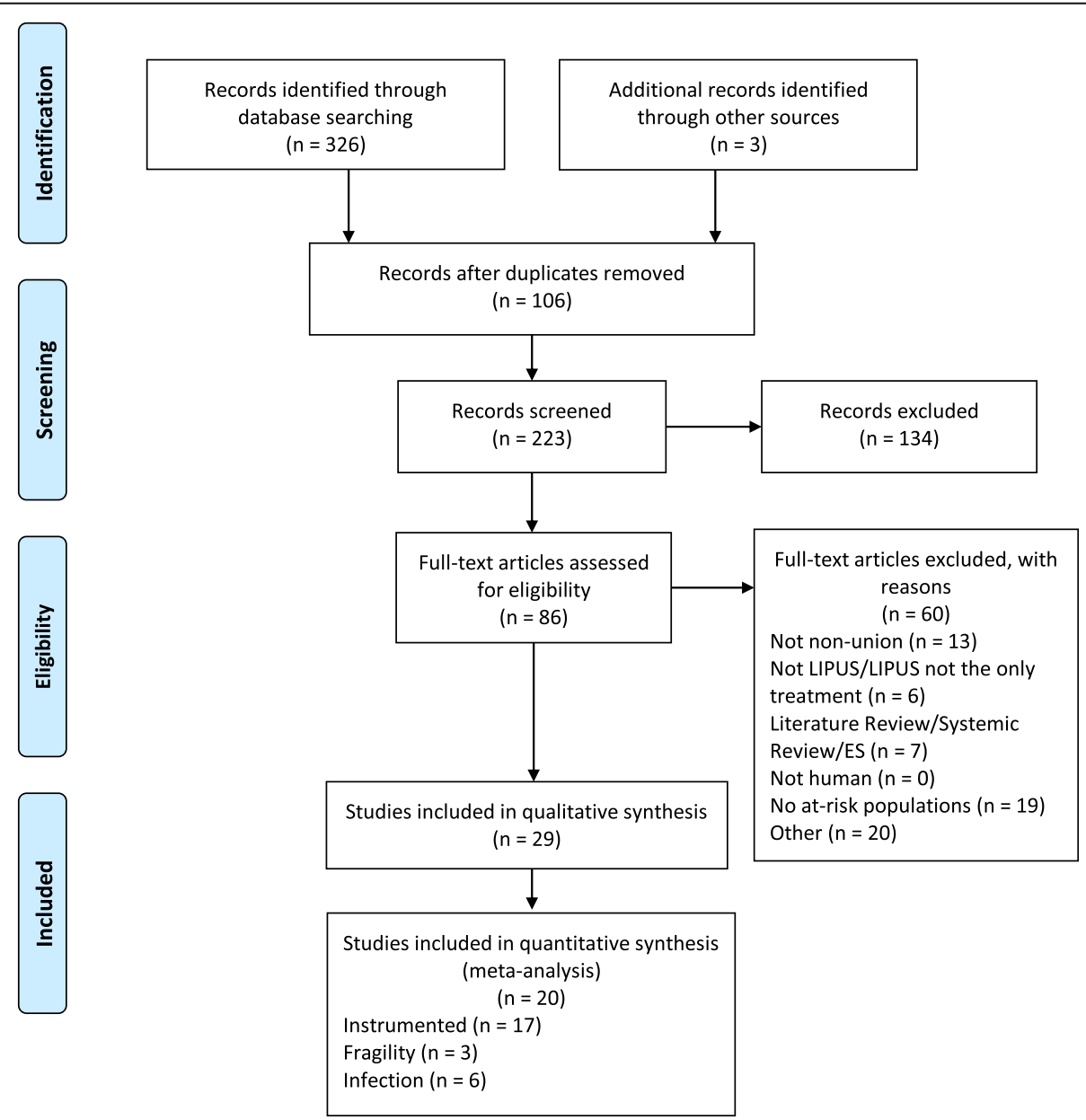

Fig. 1 Literature review flow diagram 
Table 1 Study Characteristics

\begin{tabular}{|c|c|c|c|c|c|c|c|}
\hline Article First Author/Year & Country & Study Design & $\begin{array}{l}\text { Retrospective } \\
\text { or Prospective }\end{array}$ & $\begin{array}{l}\text { Total } \\
\text { Participants } \\
\text { (n) }\end{array}$ & $\begin{array}{l}\text { Mean Age } \\
\text { (Years) }\end{array}$ & $\begin{array}{l}\% \\
\text { Female }\end{array}$ & Bones Treated (Total Study) \\
\hline Akiyama, 2011 [9] & Japan & Case Report & Retrospective & 15 & 58.9 & 91 & Femur, Hip \\
\hline $\begin{array}{l}\text { Exogen Post-Market } \\
\text { Approval - EXOGEN } \\
\text { Validation Report, } \\
2019 \text { [10] }\end{array}$ & USA & Case Series & Prospective & 158 & 61 & 93.7 & $\begin{array}{l}\text { Hamate, Scaphoid, Tibia, Fibula, } \\
\text { Ankle, Radius, Femur, Matatarsal, } \\
\text { Clavicle, Scapula, Ulna, Humerus, } \\
\text { Patella, Pelvis, Cuneiform, Talus }\end{array}$ \\
\hline Fujishiro, 2005 [11] & Japan & Case Report & Retrospective & 1 & 17 & 0 & Femur \\
\hline Gebauer, 2005 [12] & $\begin{array}{l}\text { Germany, } \\
\text { Austria }\end{array}$ & Case-control & Retrospective & 67 & 46 & 38.8 & $\begin{array}{l}\text { Tibia, Fibula, Femur, Radius, Ulna } \\
\text { Humerus, Metatarsal, Ankle, } \\
\text { Scaphoid, Clavicle, Pelvis, Calcaneus, } \\
\text { Rib, Knee }\end{array}$ \\
\hline Hemery, 2011 [13] & France & Case Series & Retrospective & 14 & 39 & 21.4 & Femur, Tibia \\
\hline Huber, 2012 [14] & Germany & Case Report & Retrospective & 1 & 19 & 0 & Phalanx \\
\hline Jingushi, 2007 [15] & Japan & Case Series & Prospective & 72 & 40.4 & 27.8 & $\begin{array}{l}\text { Humerus, Radius, Ulna, Femur, } \\
\text { Tibia }\end{array}$ \\
\hline Joshy, 2007 [16] & UK & Case Series & Retrospective & 7 & 56 & 28.6 & Tibia \\
\hline Lee, 2016 [17] & Japan & Case Report & Retrospective & 2 & 40 & 50 & Femur \\
\hline Lerner, 2004 [18] & Israel & Case Series & Retrospective & 18 & 32 & 16.7 & $\begin{array}{l}\text { Femur, Tibia, Radius, Ulna, } \\
\text { Humerus }\end{array}$ \\
\hline Lim, 2012 [19] & Malaysia & Case Report & Retrospective & 1 & 60 & 100 & Femur \\
\hline Majeed, 2019 [20] & UK & Case Series & Prospective & 47 & 56.6 & 44.7 & Tibia, Ankle, Foot \\
\hline Mayr, 2000 [21] & $\begin{array}{l}\text { USA, } \\
\text { Germany }\end{array}$ & Case Series & $\begin{array}{l}\text { Retrospective, } \\
\text { Prospective }\end{array}$ & 1359 & NR & NR & $\begin{array}{l}\text { Clavicle, Humerus, Radius, Ulna, } \\
\text { Scaphoid, } \\
\text { Femur, Tibia, Fibula, Ankle, } \\
\text { Calcaneus, } \\
\text { Tarsal naviculare, Metatarsal, } \\
\text { Foot, Other }\end{array}$ \\
\hline Mayr, 2002 [22] & Germany & Case Series & Prospective & 100 & 44 & 37 & $\begin{array}{l}\text { Clavicle, Humerus, Radius, Ulna, } \\
\text { Scaphoid, Femur, Tibia, Fibula, } \\
\text { Other }\end{array}$ \\
\hline Mirza, 2018 [23] & UK & Case Series & Retrospective & 18 & 57.6 & 50 & Foot, Ankle \\
\hline Moghaddam, 2016 [24] & Germany & Case Series & Prospective & 19 & 43 & 5.3 & $\begin{array}{l}\text { Humerus, Radius, Ulna, Femur, } \\
\text { Tibia }\end{array}$ \\
\hline Niikura, 2016 [25] & Japan & Case Report & Retrospective & 1 & 44 & 0 & Tibia \\
\hline Nolte, 2001 [26] & Netherlands & Case Series & Retrospective & 29 & 47 & 41.4 & $\begin{array}{l}\text { Tibia, Fibula, Femur, Radius, Ulna, } \\
\text { Scaphoid, Malleolus, Clavicle, } \\
\text { Humerus, Metatarsal }\end{array}$ \\
\hline Pigozzi, 2004 [27] & Italy & Case Series & Prospective & 15 & 35.5 & 20 & $\begin{array}{l}\text { Wrist, Scaphoid, Clavicle, Talus, } \\
\text { Femur, Tibia, Malleolus }\end{array}$ \\
\hline Povlsen, 2015 [28] & UK & Case Report & Retrospective & 1 & 75 & 100 & Ulna \\
\hline Ricardo, 2006 [29] & Cuba & RCT & Prospective & 21 & 26.7 & 0 & Scaphoid \\
\hline Romanò, 2006[30] & Italy & Case Series & Retrospective & 49 & NR & NR & NR \\
\hline Roussignol, 2012 [31] & France & Case Series & Retrospective & 60 & 43 & 36.7 & $\begin{array}{l}\text { Humerus, Ulna, Radius, Metacarpal, } \\
\text { Femur, Tibia, Fibula, Talus, Hallux, } \\
\text { Metatarsal, Phalanx }\end{array}$ \\
\hline Rutten, 2007 [32] & Netherlands & Case Series & Prospective & 71 & 40 & 21.1 & Tibia \\
\hline Schofer, 2010 [33] & Germany & $\mathrm{RCT}$ & Prospective & 101 & 42.6 & 23.8 & Tibia \\
\hline Waseem, 2010 [34] & Canada & Case Report & Retrospective & 1 & 77 & 100 & Femur \\
\hline Watanabe, 2013 [35] & Japan & Case Series & Retrospective & 151 & $36.5^{\mathrm{a}}$ & 27.2 & $\begin{array}{l}\text { Tibia, Fibula, Femur, Humerus, } \\
\text { Radius, Ulna }\end{array}$ \\
\hline Welch-Phillips, 2016 [36] & Ireland & Cohort & Retrospective & NR & NR & NR & NR \\
\hline Zura, 2015 [37] & USA & Case Series & Prospective & 767 & 45.8 & 45.4 & $\begin{array}{l}\text { Tibia, Femur, Radius, Ulna, Humerus, } \\
\text { Fibula, Scaphoid, Ankle, Metatarsal, } \\
\text { Foot }\end{array}$ \\
\hline
\end{tabular}


Table 2 Heal Rates for At-Risk Sub-Populations (Including Case Reports)

\begin{tabular}{|c|c|c|c|c|}
\hline Article First Author/Year & $\begin{array}{l}\text { Delayed Union or Non- } \\
\text { Union }\end{array}$ & $\begin{array}{l}\text { Total Sub-Population } \\
\text { Participants (n) }\end{array}$ & $\begin{array}{l}\text { Sub-Population } \\
\text { Participants Healed (n) }\end{array}$ & $\begin{array}{l}\text { Sub-Population } \\
\text { Heal Rate (\%) }\end{array}$ \\
\hline \multicolumn{5}{|l|}{ Instrumented } \\
\hline Akiyama, 2011 [9] & Non-union & 1 & 1 & 100 \\
\hline Akiyama, 2011 [9] & Delayed Union & 1 & 1 & 100 \\
\hline Fujishiro, 2005 [11] & Non-union & 1 & 1 & 100 \\
\hline Gebauer, 2005 [12] & Non-union & 43 & 38 & 88.4 \\
\hline Hemery, 2011 [13] & Non-union & 14 & 11 & 78.6 \\
\hline Huber, 2012 [14] & Non-union & 1 & 1 & 100 \\
\hline Jingushi, 2007 [15] & Non-union & 32 & 21 & 65.6 \\
\hline Jingushi, 2007ª [15] & Delayed Union & 40 & 33 & 82.5 \\
\hline Joshy, 2007 [16] & Non-union & 5 & 5 & 100 \\
\hline Lee, 2016 [17] & Non-union & 1 & 1 & 100 \\
\hline Lee, 2016 [17] & Delayed Union & 1 & 1 & 100 \\
\hline Lerner, 2004 [18] & Delayed Union & 16 & 14 & 87.5 \\
\hline Lim, 2012 [19] & Non-union & 1 & 1 & 100 \\
\hline Majeed, 2019 [20] & Non-union & 15 & 10 & 66.7 \\
\hline Mayr, 2000 [21] & Delayed Union & NR & NR & 91.7 \\
\hline Mayr, 2002 [22] & $\begin{array}{l}\text { Combined Delayed } \\
\text { Union \& Non-union }\end{array}$ & 41 & 40 & 97.6 \\
\hline Mirza, 2018 [23] & $\begin{array}{l}\text { Combined Delayed } \\
\text { Union \& Non-union }\end{array}$ & 18 & 12 & 66.7 \\
\hline Moghaddam, 2016 [24] & Non-union & 19 & 11 & 57.9 \\
\hline Niikura, 2016 [25] & Non-union & 1 & 1 & 100 \\
\hline Nolte, 2001 [26] & Non-union & 21 & 18 & 85.7 \\
\hline Pigozzi, 2004 [27] & Non-union & 8 & 8 & 100 \\
\hline Povlsen, 2015 [28] & Non-union & 1 & 1 & 100 \\
\hline Ricardo, 2006 [29] & Non-union & 10 & 10 & 100 \\
\hline Roussignol, 2012 [31] & Non-union & 59 & 52 & 88.1 \\
\hline Rutten, 2007 [32] & Non-union & 45 & 32 & 71.1 \\
\hline Schofer, $2010^{a}$ [33] & Delayed Union & 51 & 33 & 64.7 \\
\hline Waseem, 2010 [34] & Non-union & 2 & 2 & 100 \\
\hline Watanabe, 2013 [35] & Non-union & 42 & 27 & 64.3 \\
\hline Watanabe, 2013 [35] & Delayed Union & 92 & 69 & 75 \\
\hline Welch-Phillips, 2016 [36] & Delayed Union & NR & NR & 73.5 \\
\hline Zura, 2015 [37] & Non-union & 222 & 189 & 85.1 \\
\hline \multicolumn{5}{|l|}{ Infection } \\
\hline Fujishiro, 2005 [11] & Non-union & 1 & 1 & 100 \\
\hline Hemery, 2011 [13] & Non-union & 6 & 4 & 66.7 \\
\hline Joshy, 2007 [16] & Non-union & 2 & 2 & 100 \\
\hline Lim, 2012 [19] & Non-union & 1 & 1 & 100 \\
\hline Mayr, 2000 [21] & $\begin{array}{l}\text { Combined Delayed } \\
\text { Union \& Non-union }\end{array}$ & 13 & 13 & 100 \\
\hline Niikura, 2016 [25] & Non-union & 1 & 1 & 100 \\
\hline Nolte, 2001 [26] & Non-union & 2 & 2 & 100 \\
\hline Romanò, 2006 & Non-union & 49 & 39 & 79.6 \\
\hline
\end{tabular}


Table 2 Heal Rates for At-Risk Sub-Populations (Including Case Reports) (Continued)

\begin{tabular}{|c|c|c|c|c|}
\hline Article First Author/Year & $\begin{array}{l}\text { Delayed Union or Non- } \\
\text { Union }\end{array}$ & $\begin{array}{l}\text { Total Sub-Population } \\
\text { Participants (n) }\end{array}$ & $\begin{array}{l}\text { Sub-Population } \\
\text { Participants Healed (n) }\end{array}$ & $\begin{array}{l}\text { Sub-Population } \\
\text { Heal Rate (\%) }\end{array}$ \\
\hline Rutten, 2007 [32] & Non-union & 6 & 3 & 50 \\
\hline Waseem, 2010 [34] & Non-union & 1 & 1 & 100 \\
\hline \multicolumn{5}{|l|}{ Fragility } \\
\hline Joshy, 2007 [16] & Non-union & 1 & 1 & 100 \\
\hline Mayr, 2000 [21] & $\begin{array}{l}\text { Combined Delayed } \\
\text { Union \& Non-union }\end{array}$ & 43 & 37 & 87 \\
\hline $\begin{array}{l}\text { Exogen Post-Market Approval - EXOGEN } \\
\text { Validation Report, } 2019 \text { [10] }\end{array}$ & Non-union & 158 & 145 & 91.8 \\
\hline
\end{tabular}

Abbreviations: NR Not Reported

${ }^{a}$ Overall heal rate is reported as the authors did not provide a subgroup analysis of heal rate in instrumented non-union fractures

included in the analysis of healing rate for instrumented fractures, 78 patients with infected non-unions, and 202 patients with fragility fracture non-unions. Instrumented non-unions had a pooled healing rate of $82 \%(95 \% \mathrm{CI}$ : 76 to $87 \%$ ), with substantial heterogeneity observed $\left(\mathrm{I}^{2}=78 \%\right.$ ) (Fig. 2). Infected non-unions had a similar pooled healing rate of $82 \%$ (95\% CI: 70 to $95 \%$ ), with moderate heterogeneity observed $\left(\mathrm{I}^{2}=49 \%\right)$ (Fig. 3). Fragility fracture non-unions had a pooled healing rate of 91\% (95\% CI: 87 to 95\%), with no heterogeneity observed $\left(\mathrm{I}^{2}=0 \%\right)$ (Fig. 4$)$.

\section{Discussion}

The results of this study demonstrate that, given the available literature, LIPUS treatment healed $82 \%$ of instrumented non-unions, $82 \%$ of infected non-unions, and $91 \%$ of fragility fracture non-unions. These findings support the use of LIPUS for conservative non-union management within these non-union subgroups, as these healing rates are similar to those seen for LIPUS use within the general non-union literature [38]. Previous studies have suggested that Exogen non-union heal rates are 84 to $90 \%$, with mean healing times of 178 days [6]. In comparison, surgical management of non-unions has also demonstrated comparable healing rates and comparable times to heal a non-union [6]. It is important to consider the improved socioeconomic implications of healing a non-union nonoperatively within these groups, as resorting immediately to surgical treatment may pose unnecessary costs to the health care system. It is also important to measure the quality of life implications that would be also improved with a successful non-operative LIPUS treatment protocol. With over $80 \%$ of patients demonstrating a healed non-union with LIPUS,

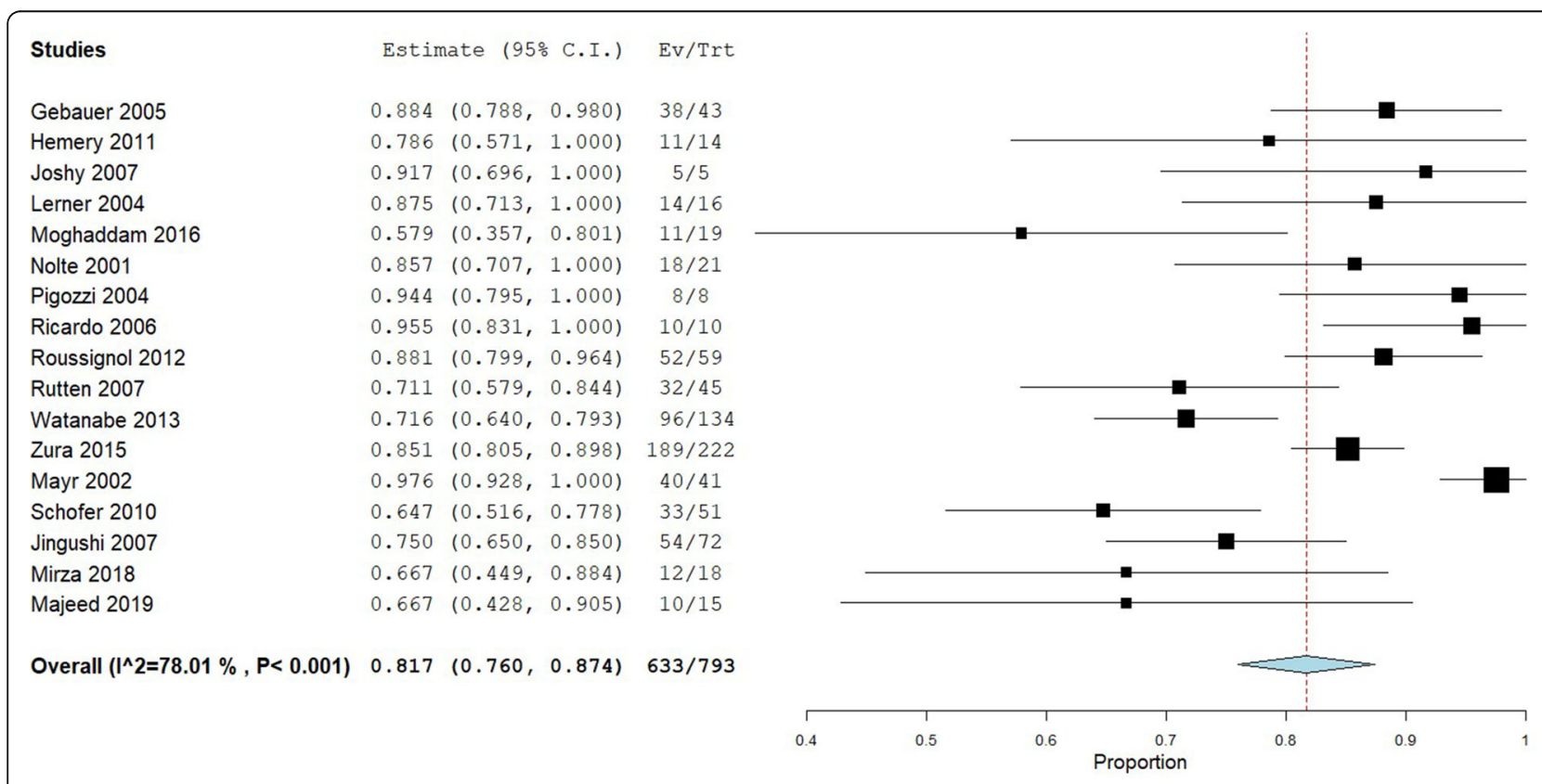

Fig. 2 Shows the pooled proportion for instrumented non-union 


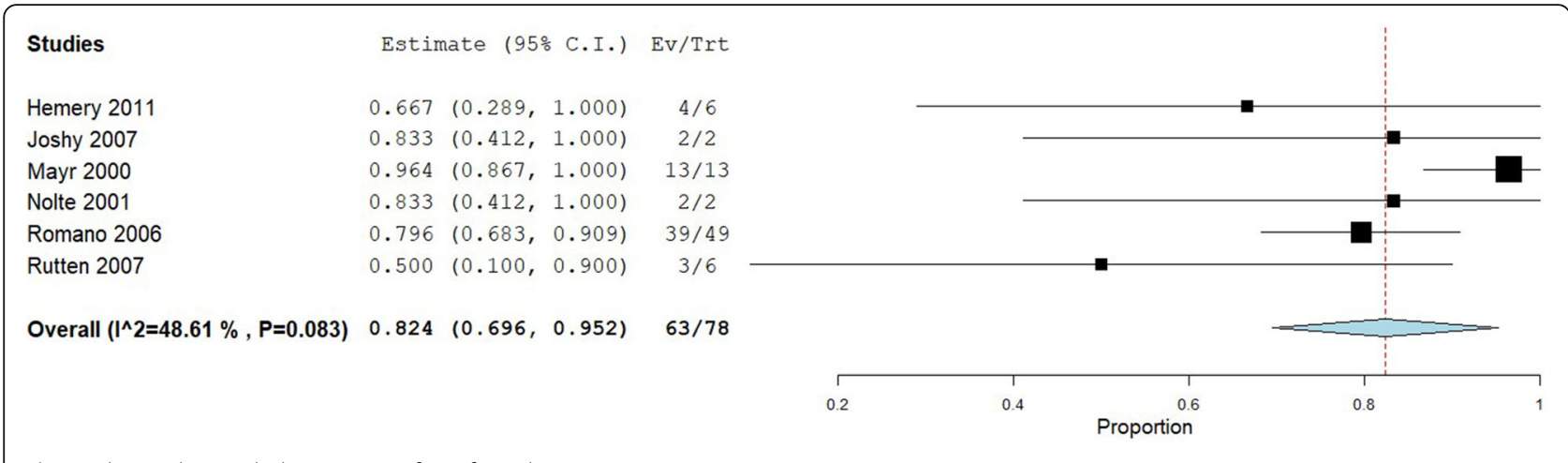

Fig. 3 Shows the pooled proportion for infected non-union

regardless of infection, instrumentation, or fragility fracture, the costs of surgical management may be avoidable in a large proportion of non-union patients.

This strength of this investigation is its comprehensive review of the currently available literature. The systematic search and screening process provide certainty that all available literature has been documented and summarized within this study. Additionally, this study is strengthened by its applicability and direct implications for current clinical orthopedic practice. The socioeconomic costs of surgical management of non-unions can be large, and this study provides evidence that conservative non-union treatment is a viable option that would limit the exposure to these exorbitant costs.

Despite these strengths, there are a number of key limitations that must be considered when interpreting these findings. The weaknesses of this study will be detailed as follows: 1) the current available evidence is primarily from case series data. There is a lack of high quality, level 1 evidence that assesses the effect of LIPUS on non-union management. This precludes the ability to comparatively assess LIPUS with a published prospective study. Within this form of pooled proportion analysis there is no comparator, thus making all included data, including that from RCT and cohort studies, should still be considered as low quality. 2) the classification of nonunion may not be the same within each of the included studies. While all studies identified their patients as having non/delayed union, they did not all use the exact same criteria to make this classification. Although this creates possible heterogeneity across studies, they all generally classified non-union in patients as a stop in biological healing progression. While criteria may have differed slightly, the findings can be reasonably attributed to non-union patients in general. 3) Another consideration with regard to the between study heterogeneity that was observed is the inclusion of all bone types in this analysis. While differences between healing rates across bones may exist, the healing rates are consistently beneficial across studies and bones, which provides justification for pooling.

It would be beneficial for future investigations to define delayed and non-unions and provide a randomized comparison between a LIPUS non-surgical treatment protocol and surgical treatment of non-unions. This would help limit the impact that prognostic variables may have on the results, as can be seen within the majority of the current non-randomized literature. Additional analyses of the direct socioeconomic cost implications of LIPUS implementation compared to surgical intervention within non-union patient groups and subgroups would also be of benefit. This would allow more clear understanding of the potential for a LIPUS nonunion treatment protocol to reduce costs and reduce the impact of a non-union to the health care system, patients and their families. It is important to consider

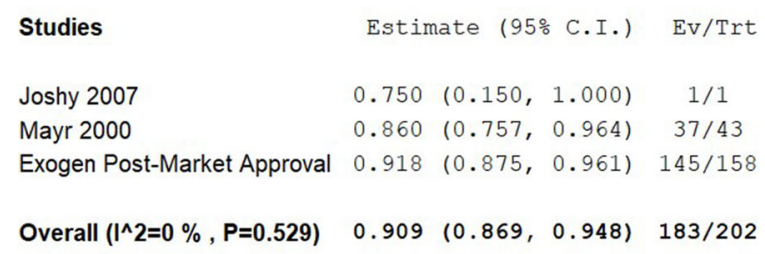

Fig. 4 Shows the pooled proportion for fragility non-union 
other relevant outcomes in future investigations. While reporting of adverse events is minimal with regard to LIPUS, studies comparing LIPUS to other treatment options needs to weigh the potential adverse events of other treatments relative to LIPUS. For example, surgical interventions may demonstrate successful healing rates, but the possible adverse events would also need to be taken into consideration. Compliance with LIPUS treatment protocols is also an important aspect of treatment, as a lack of compliance may result in less than optimal healing outcomes.

\section{Conclusion}

This study has provided a thorough overview of the current literature on LIPUS treatment for instrumented, infected, and fragility non-unions. Across all current evidence, non-union healing rates for these subgroups were $82 \%$ in instrumented, $82 \%$ in infected, and $91 \%$ in fragility non-union patients. Due to the large socioeconomic and quality of life implications for surgical management of these patient subgroups, LIPUS treatment should be considered as a conservative treatment option.

\section{Supplementary Information}

The online version contains supplementary material available at https://doi. org/10.1186/s12891-021-04322-5.

Additional file 1.

\section{Acknowledgements}

Medical writing support provided by Global Research Solutions Inc.

\section{Authors' contributions}

$\mathrm{RL}, \mathrm{MB}$, and $\mathrm{RZ}$ aided in conception, design, interpretation, provided input and revisions to the manuscript, approved of, and agreed to be accountable for the integrity of the work. MP aided in conception, design, analysis, interpretation, provided writing and revisions to the manuscript, approved of, and agreed to be accountable for the integrity of the work.

\section{Funding}

This study was supported by a grant from Bioventus.

Availability of data and materials

All data analyzed during this study are included in this published article.

\section{Declarations}

Ethics approval and consent to participate

Not applicable.

\section{Consent for publication}

Not applicable.

\section{Competing interests}

Ross Leighton: Speaker Bureau--Bioventis, Smith and Nephew, Johnson and Johnson, Biomet Zimmer, Bio composites. Research Grants- Johnson and Johnson, Smith and Nephew, Stryker.

Mark Phillips: Employee of Global Research Solutions Inc.

Mohit Bhandari: Grants from Bioventus during the conduct of this work, personal fees from AgNovos Healthcare, grants and personal fees from Sanofi Aventis, grants and personal fees from Stryker, personal fees from
Pendopharm, grants from Acumed, DJ Orthopedics, Titan Spine, and Flexion Therapeutics, outside the submitted work.

Robert Zura: Personal fees from Bioventus, Osteocentric, Smith and Nephew, and non-financial support from Stryker, outside the submitted work.

\section{Author details}

'Division of Orthopaedic Surgery, Dalhousie University, Halifax, Nova Scotia, Canada. ${ }^{2}$ Department of Health Research Methods, Evidence, and Impact, McMaster University, Hamilton, Ontario, Canada. ${ }^{3}$ Division of Orthopaedic Surgery, McMaster University, Hamilton, Ontario, Canada. ${ }^{4}$ Department of Orthopaedic Surgery, Louisiana State University Health Sciences Center, New Orleans, Louisiana, USA.

Received: 18 September 2020 Accepted: 5 May 2021

Published online: 11 June 2021

\section{References}

1. Zura R, Xiong Z, Einhorn T, Watson JT, Ostrum RF, Prayson MJ, et al. Epidemiology of fracture nonunion in 18 human bones. JAMA Surg. 2016; 151(11):e162775. https://doi.org/10.1001/jamasurg.2016.2775

2. Zura R, Kaste SC, Heffernan MJ, Accousti WK, Gargiulo D, Wang Z, et al. Risk factors for nonunion of bone fracture in pediatric patients: an inception cohort study of 237,033 fractures. Medicine (Baltimore). 2018;97(31):e11691. https://doi.org/10.1097/MD.0000000000011691.

3. Zura R, Braid-Forbes MJ, Jeray K, Mehta S, Einhorn TA, Watson JT, et al. Bone fracture nonunion rate decreases with increasing age: a prospective inception cohort study. Bone. 2017;95:26-32. https://doi.org/10.1016/j. bone.2016.11.006.

4. Ekegren $\mathrm{CL}$, Edwards ER, de Steiger R, Gabbe BJ. Incidence, costs and predictors of non-union, delayed union and mal-union following long bone fracture. Int J Environ Res Public Health. 2018;15(12). https://doi.org/10.3390/ ijerph15122845.

5. Antonova $\mathrm{E}$, Le TK, Burge R, Mershon J. Tibia shaft fractures: costly burden of nonunions. BMC Musculoskelet Disord. 2013;14(1):42. https://doi.org/10.11 86/1471-2474-14-42.

6. Higgins A, Glover M, Yang Y, Bayliss S, Meads C, Lord J. EXOGEN ultrasound bone healing system for long bone fractures with non-union or delayed healing: a NICE medical technology guidance. Appl Health Econ Health Policy. 2014;12(5):477-84. https://doi.org/10.1007/s40258-014-0117-6.

7. Chaudhary MM. Infected nonunion of tibia. Indian J Orthop. 2017;51(3):25668. https://doi.org/10.4103/ortho.IJOrtho_199_16.

8. Liberati A, Altman DG, Tetzlaff J, Mulrow C, Gøtzsche PC, loannidis JPA, et al. The PRISMA statement for reporting systematic reviews and meta-analyses of studies that evaluate health care interventions: explanation and elaboration. PLoS Med. 2009;6(7):e1000100. https://doi.org/10.1371/journal. pmed. 1000100

9. Akiyama H, Kawanabe K, Yamamoto K, et al. Cemented total hip arthroplasty with subtrochanteric femoral shortening transverse osteotomy for severely dislocated hips: outcome with a 3- to 10-year follow-up period. J Orthop Sci Off J Jpn Orthop Assoc. 2011;16(3):270-7. https://doi.org/10.1 007/s00776-011-0049-z.

10. Bioventus Exogen label expansion indications for use design validation report. RPT-000879. LLC, Durham: Bioventus; 2019. (unpublished)

11. Fujishiro T, Matsui N, Yoshiya S, Fujioka H, Tsunoda M, Kurosaka M. Treatment of a bone defect in the femoral shaft after osteomyelitis using low-intensity pulsed ultrasound. Eur J Orthop Surg Traumatol. 2005;15(3): 244-6. https://doi.org/10.1007/s00590-005-0235-9.

12. Gebauer D, Mayr E, Orthner E, Ryaby JP. Low-intensity pulsed ultrasound: effects on nonunions. Ultrasound Med Biol. 2005;31(10):1391-402. https:// doi.org/10.1016/j.ultrasmedbio.2005.06.002.

13. Hemery X, Ohl X, Saddiki R, Barresi L, Dehoux E. Low-intensity pulsed ultrasound for non-union treatment: a 14-case series evaluation. Orthop Traumatol Surg Res OTSR. 2011;97(1):51-7. https://doi.org/10.1016/j.otsr.20 0.09 .016 .

14. Huber M, Prantl L, Gehmert S. Successful treatment of nonunion in severe finger injury with low-intensity pulsed ultrasound (LIPUS): a case report. J Med Case Rep. 2012;6(1):209. https://doi.org/10.1186/1752-1947-6-209.

15. Jingushi S, Mizuno K, Matsushita T, Itoman M. Low-intensity pulsed ultrasound treatment for postoperative delayed union or nonunion of long bone fractures. J Orthop Sci Off J Jpn Orthop Assoc. 2007:12(1):35-41. https://doi.org/10.1007/s00776-006-1080-3. 
16. Joshy S, Gopalan S, Deshmukh SC. Low-intensity pulsed ultrasound in the treatment of tibial non-union. Eur J Orthop Surg Traumatol. 2007;17(4):3636. https://doi.org/10.1007/s00590-007-0199-z.

17. Lee SY, Niikura T, Iwakura T, Kuroda R, Kurosaka M. Treatment of ununited femoral neck fractures in young adults using low-intensity pulsed ultrasound: report of 2 cases. Int J Surg Case Rep. 2016;21:59-62. https://doi. org/10.1016/j.jijscr.2016.02.020.

18. Lerner A, Stein H, Soudry M. Compound high-energy limb fractures with delayed union: our experience with adjuvant ultrasound stimulation (exogen). Ultrasonics. 2004;42(1-9):915-7. https://doi.org/10.1016/j.ultras.2 003.11.014.

19. Lim W, Cheong M, Phang H, Ramanathan R. Low-intensity pulsed ultrasound (lipus) treatment for non union subtrochanteric fracture of femur: a case report. Malaysian Orthopaedic Association Scientific Metting 2012. Conference Abstract and Poster Presentation. 2012. p. 39.

20. Majeed H, Karim T, Davenport J, Karski M, Smith R, Clough TM. Clinical and patient-reported outcomes following low intensity pulsed ultrasound (LIPUS, exogen) for established post-traumatic and post-surgical nonunion in the foot and ankle. Foot Ankle Surg Off J Eur Soc Foot Ankle Surg. 2019; 26(4):405-11. https://doi.org/10.1016/j.fas.2019.05.009.

21. Mayr E, Frankel V, Rüter A. Ultrasound--an alternative healing method for nonunions? Arch Orthop Trauma Surg. 2000;120(1-2):1-8. https://doi.org/1 $0.1007 / \mathrm{pl} 00021234$

22. Mayr E, Möckl C, Lenich A, Ecker M, Rüter A. Is low intensity ultrasound effective in treatment of disorders of fracture healing? Unfallchirurg. 2002; 105(2):108-15. https://doi.org/10.1007/s001130100301.

23. Mirza YH, Teoh KH, Golding D, Wong JF, Nathdwarawala Y. Is there a role for low intensity pulsed ultrasound (LIPUS) in delayed or nonunion following arthrodesis in foot and ankle surgery? Foot Ankle Surg Off $J$ Eur Soc Foot Ankle Surg. 2019;25(6):842-8. https://doi.org/10.1016/j.fas.2 018.11.004.

24. Moghaddam A, Yildirim TM, Westhauser F, Danner W, Swing T, Bruckner T, et al. Low intensity pulsed ultrasound in the treatment of long bone nonunions: evaluation of cytokine expression as a tool for objectifying nonunion therapy. J Orthop. 2016;13(4):306-12. https://doi.org/10.1016/j. jor.2016.06.028.

25. Niikura T, Yang Lee S, Iwakura T, Kurosaka M. 8. Low-intensity pulsed ultrasound (LIPUS) treatment for the patient with bone reconstruction by the masquelet technique using RIA. J Orthop Trauma. 2016;30(8):S4. https:// doi.org/10.1097/01.bot.0000489981.32706.91.

26. Nolte PA, van der Krans A, Patka P, Janssen IM, Ryaby JP, Albers GH. Lowintensity pulsed ultrasound in the treatment of nonunions. J Trauma. 2001; 51(4):693-702; discussion 702-703. https://doi.org/10.1097/00005373-20011 0000-00012

27. Pigozzi F, Moneta MR, Giombini $\mathrm{A}$, et al. Low-intensity pulsed ultrasound in the conservative treatment of pseudoarthrosis. J Sports Med Phys Fitness. 2004;44(2):173-8.

28. Povlsen SD, Povlsen B. Low-intensity pulsed ultrasound treatment as an alternative to vascular bone graft surgery for a 5-year-long ulnar non-union in a patient with haemochromatosis. BMJ Case Rep. 2015;2015. https://doi. org/10.1136/bcr-2015-211950.

29. Ricardo M. The effect of ultrasound on the healing of muscle-pediculated bone graft in scaphoid non-union. Int Orthop. 2006;30(2):123-7. https://doi. org/10.1007/s00264-005-0034-2.

30. Romano C, Zavatarelli AM. Biophysical treatment of septic nonunions. Arch Ortop Reumatol. 2006. p. 12-3. https://doi.org/10.1007/s10261-006-0097-7.

31. Roussignol X, Currey C, Duparc F, Dujardin F. Indications and results for the exogen ${ }^{T M}$ ultrasound system in the management of non-union: a 59-case pilot study. Orthop Traumatol Surg Res OTSR. 2012;98(2):206-13. https://doi. org/10.1016/j.otsr.2011.10.011.

32. Rutten S, Nolte PA, Guit GL, Bouman DE, Albers GHR. Use of low-intensity pulsed ultrasound for posttraumatic nonunions of the tibia: a review of patients treated in the Netherlands. J Trauma. 2007;62(4):902-8. https://doi. org/10.1097/01.ta.0000238663.33796.fb.

33. Schofer MD, Block JE, Aigner J, Schmelz A. Improved healing response in delayed unions of the tibia with low-intensity pulsed ultrasound: results of a randomized sham-controlled trial. BMC Musculoskelet Disord. 2010;11(1):229. https://doi.org/10.1186/1471-2474-11-229.

34. Waseem Z, Ford M, Syed K, Flannery J. Chronic nonunion in a patient with bilateral supracondylar distal femur fractures treated successfully with twice daily low-intensity pulsed ultrasound. PM R. 2010;2(2):159-61. https://doi. org/10.1016/j.pmrj.2009.11.008

35. Watanabe Y, Arai Y, Takenaka N, Kobayashi M, Matsushita T. Three key factors affecting treatment results of low-intensity pulsed ultrasound for delayed unions and nonunions: instability, gap size, and atrophic nonunion. J Orthop Sci Off J Jpn Orthop Assoc. 2013;18(5):803-10. https://doi.org/10.1 007/s00776-013-0415-0.

36. Welch-Phillips A, Kennedy C, Harty J, Athar M. P25 assessment of lowintensity pulsed ultrasound on fracture healing as used in a level-1 trauma Centre - injury. Injury. 2016;47(5):S34. https://doi.org/10.1016/S0020-1383 (16)30576-9.

37. Zura R, Della Rocca GJ, Mehta S, Harrison A, Brodie C, Jones J, et al. Treatment of chronic ( $>1$ year) fracture nonunion: heal rate in a cohort of 767 patients treated with low-intensity pulsed ultrasound (LIPUS). Injury. 2015:46(10):2036-41. https://doi.org/10.1016/j.injury.2015.05.042.

38. Leighton R, Watson JT, Giannoudis P, Papakostidis C, Harrison A, Steen RG. Healing of fracture nonunions treated with low-intensity pulsed ultrasound (LIPUS): a systematic review and meta-analysis. Injury. 2017;48(7):1339-47. https://doi.org/10.1016/j.injury.2017.05.016.

\section{Publisher's Note}

Springer Nature remains neutral with regard to jurisdictional claims in published maps and institutional affiliations.
Ready to submit your research? Choose BMC and benefit from:

- fast, convenient online submission

- thorough peer review by experienced researchers in your field

- rapid publication on acceptance

- support for research data, including large and complex data types

- gold Open Access which fosters wider collaboration and increased citations

- maximum visibility for your research: over $100 \mathrm{M}$ website views per year

At BMC, research is always in progress.

Learn more biomedcentral.com/submissions 